\title{
Objective Outcomes of Closed Reduction According to the Type of Nasal Bone Fracture
}

\author{
Chang Min Kang, \\ Dong Gil Han \\ Department of Plastic and Reconstructive \\ Surgery, School of Medicine, Catholic \\ University of Daegu, Daegu, Korea
}

\begin{abstract}
Background: Nasal fractures have a tendency of resulting in structural or functional complications, and the results can vary according to the type of nasal bone fracture. The aim of this study was to evaluate the objective postoperative results according to the type of nasal bone fractures.

Methods: We reviewed 313 patients who had a closed reduction of nasal bone fracture. The classification of nasal bone fracture by Stranc and Robertson was used to characterize the fracture type: frontal impact group type I (FI), frontal impact group type II (FII), lateral impact group type I (LI), lateral impact group type II (LII), and comminuted fracture group (C). For each patient, we tried to use the same axial image section of computed tomographic (CT) scans before and immediately after operation. Postoperative outcomes were classified into 4 grades: excellent $(E)$, good $(G)$, fair $(F)$, and poor $(P)$. We also analyzed postoperative complications by fracture type.

Results: Regarding the postoperative CT images, 189 subjects showed E results, 99 subjects showed G, 18 subjects showed $F$, and 7 subjects showed $P$ reduction. The rate of operation results graded as $\mathrm{E}$ by each fracture type was $66.67 \%$ in $\mathrm{FI}, 52.0 \%$ in $\mathrm{FII}$, $64.21 \%$ in LI, $62.79 \%$ in LII, and $21.74 \%$ in C. Complications of FI $(7.14 \%)$, LII (13.95\%), and C (13.04\%) groups occurred more than in the FII (4.00\%) and LI (4.21\%) groups.

Conclusion: It seems that the operation result by fracture type was better in the $\mathrm{FI}, \mathrm{LI}$, and LII type than the FII and C type; after one month, however, LII type showed more complications than other types. The septal fracture can be thought to affect early reduction results in nasal bone fractures.
\end{abstract}

Keywords: Nasal bone / Surgery / Treatment outcome

\section{INTRODUCTION}

The nose is an anteriorly protruding structure, which results in it being the facial feature most commonly subject to fracture. However, postoperative results are known to be less satisfactory compared to those of other facial fractures [1-4].

Nasal fracture often results in structural or functional complications, and surgical results can vary depending on the type of nasal bone fracture and/or the presence of septal fracture or devi-

Correspondence: Dong Gil Han

Department of Plastic and Reconstructive Surgery, Catholic University of Daegu, School of Medicine, 33 Duryugongwon-ro 17-gil, Nam-gu, Daegu 42472, Korea

E-mail: dghan1001@cu.ac.kr

Received November 27, 2016 / Revised March 7, 2017 / Accepted March 7, 2017 ation, even after the operation [5].

The aim of this study was to evaluate objective postoperative results and complications according to the type of nasal bone fracture with or without the presence of preoperative septal fracture or deviation.

\section{METHODS}

\section{Patients}

A database of patients who had undergone closed reduction between March 2013 and June 2015 was reviewed; 313 patients who had isolated nasal bone fractures were included in the study. 

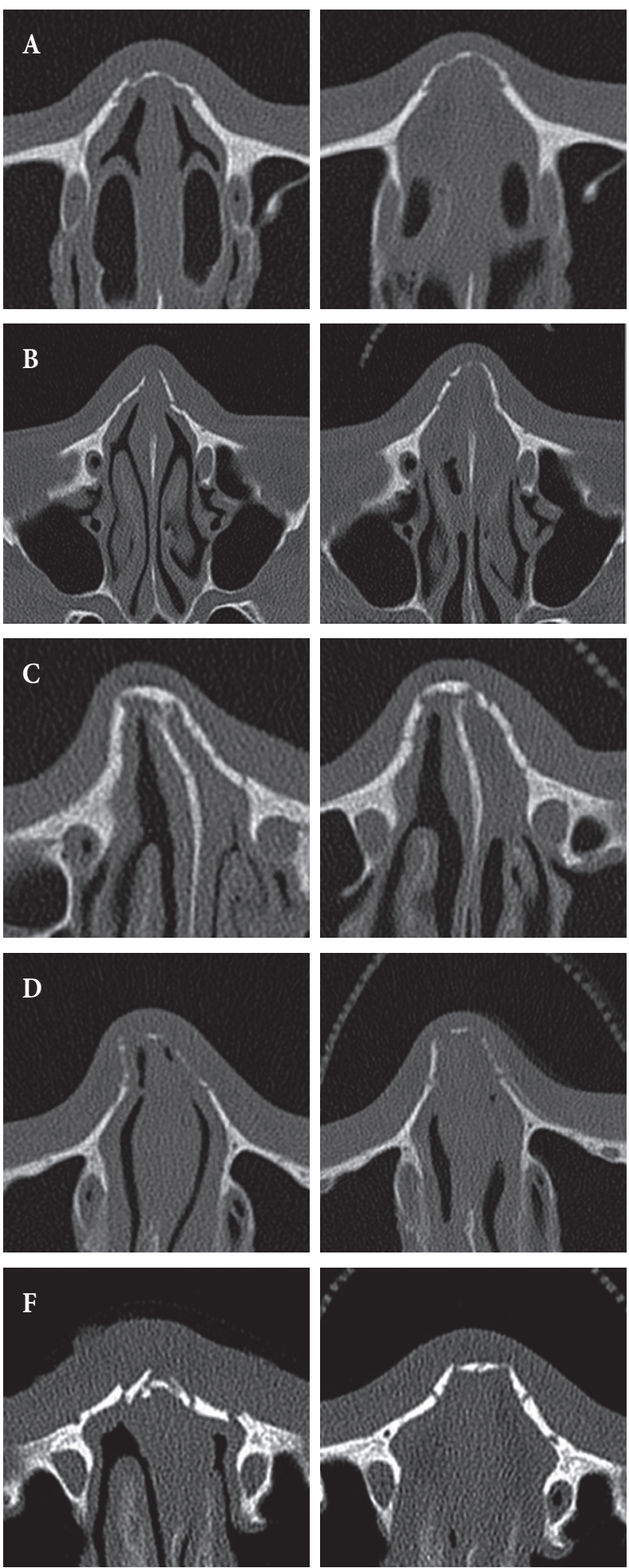

Fig. 1. Preoperative and immediate post reduction computed tomographic (CT) images (indicating excellent results) in the five types of nasal bone fractures. (A) Preoperative and immediate post reduction CT images of frontal impact group type I (FI). (B) Preoperative and immediate post reduction CT images of frontal impact group type II (FII). (C) Preoperative and immediate post reduction CT images of lateral impact group type I (LI). (D) Preoperative and immediate post reduction CT images of lateral impact group type II (LII). (E) Preoperative and immediate post reduction $\mathrm{CT}$ images of comminuted fracture group $(\mathrm{C})$. 


\section{Surgical technique}

Under general anesthesia, all patients were operated on with closed reduction by the same surgeon. If septal fracture or deviation was existed, we reducted it conservatively using Asch forcep, nasal speculum and No. 3 knife handle wrapped with Vaseline gauze. In order to support the reducted bone fragments, we used Vaseline roll gauze in the dorsal nasal cavity after reduction and Merocel in nasal airways. External nasal thermo-splints were applied [6].

\section{Assessment methods}

The classification of nasal bone fracture by Stranc and Robertson [7] was used to characterize the fracture type:

Frontal impact group type I (FI): only the lower end of the nasalbones.

Frontal impact group type /I (FII): proximal portion of nasal bone $\&$ frontal process of maxilla.

Lateral impact group type I (LI): unilateral displacement of nasal bone into the nasal cavity.

Lateral impact group type II (LII): moderate internal displacement of the ipsilateral nasal bone accompanied by some outward displacement of the contralateral nasal bone

Comminuted fracture group $(C)$ : multiple segmental fracture with telescoping and depression (Fig. 1).

For each patient, we tried to use the same axial $1 \mathrm{~mm}$ sliced image section of computed tomographic (CT) scans from a dual 128-channel CT SOMATOM Definition Flash (Siemens Industry, Munich, Germany) across the intervals (before and immediate after surgery) to allow, as much as possible, an objective com- parison of outcomes. Postoperative outcomes were evaluated in the manner listed below (Table 1) [8].

Excellent: nasal deviation is absent; arch shape is smooth; no observation of malalignment of the fracture segment.

Good: nasal deviation is absent; arch shape is smooth; malalignment is present, but with either a one-segment irregularity or displacement.

Fair: nasal deviation is absent; arch shape is smooth; malalignment is present, with both bony irregularity and displacement.

Poor: nasal deviation is present; arch shape is not smooth and with two segments of bony irregularity and displacement.

Variables were compared using the chi-square test with Bonferroni correction for multiple comparison (SPSS ver. 19.0, IBM, Armonk, NY, USA). The $p$-values $<0.05$ were considered to indicate statistical significance.

\section{RESULTS}

\section{Demographics}

Of the 313 patients, 241 were male and 72 were female. Regarding gender distribution, all types of fractures mostly occurred in males. The mean age was 32.1 years. Seventy-seven of the fractures were caused by bumping, 72 were caused by slips or falls, 67 were the result of beatings, 53 were caused by sports activities, and 44 were caused by traffic accidents (Table 2).

\section{Types of fractures}

Among the 313 patients, 109 belonged to the frontal impact groups: FI ( $\mathrm{n}=84$ patients) and FII ( $\mathrm{n}=25)$; 181 patients belonged to

Table 1. The classification criteria according to the results of closed reductions

\begin{tabular}{|c|c|c|c|c|}
\hline Criteria & Excellent & Good & Fair & Poor \\
\hline Deviation & - & - & - & + \\
\hline Overall shape of arch & Smooth & Smooth & Smooth & Irregular \\
\hline Malalignment of fracture segment & - & + & + & + \\
\hline Bony irregularity & - & One segment or & One segment and & One or two segment and \\
\hline Bony displacement & - & One segment & One segment & One or two segment \\
\hline
\end{tabular}

Reprinted from Lee et al. Arch Craniofac Surg 2014;15:63-9 [8]. 
the lateral impact groups: LI ( $\mathrm{n}=95)$ and LII $(\mathrm{n}=86)$. The remaining 23 subjects were classified as being in the C group (Table 2).

\section{Operation results}

Regarding the postoperative CT images, 189 patients showed excellent reduction, 99 subjects showed good reduction, 18 subjects showed fair reduction and 7 subjects showed poor reduction. The proportions of excellent results in each type were $66.67 \%$ in FI, $52.00 \%$ in FII, 64.21\% in LI, 62.79\% in LII, and 21.74\% in C type (Table 3). The $p$-value of the difference between each proportion of excellent results by fracture type was $<0.001$, which showed a statistically significant difference. To compare the difference of the proportion of excellent results by the fracture type, we did a post-mortem analysis. Our examination revealed that the proportion of excellent results of the FI, LI, and LII fracture types were statistically significantly higher than that of the FII fracture type and that of the FII type were statistically significantly higher than that of the $\mathrm{C}$ fracture type. However, there were no statistically significant differences in the proportion of excellent results between the FI, LI and LII groups (Table 4).

The proportions of septal fracture in each type were $53.57 \%$ in

Table 2. Patient demographics

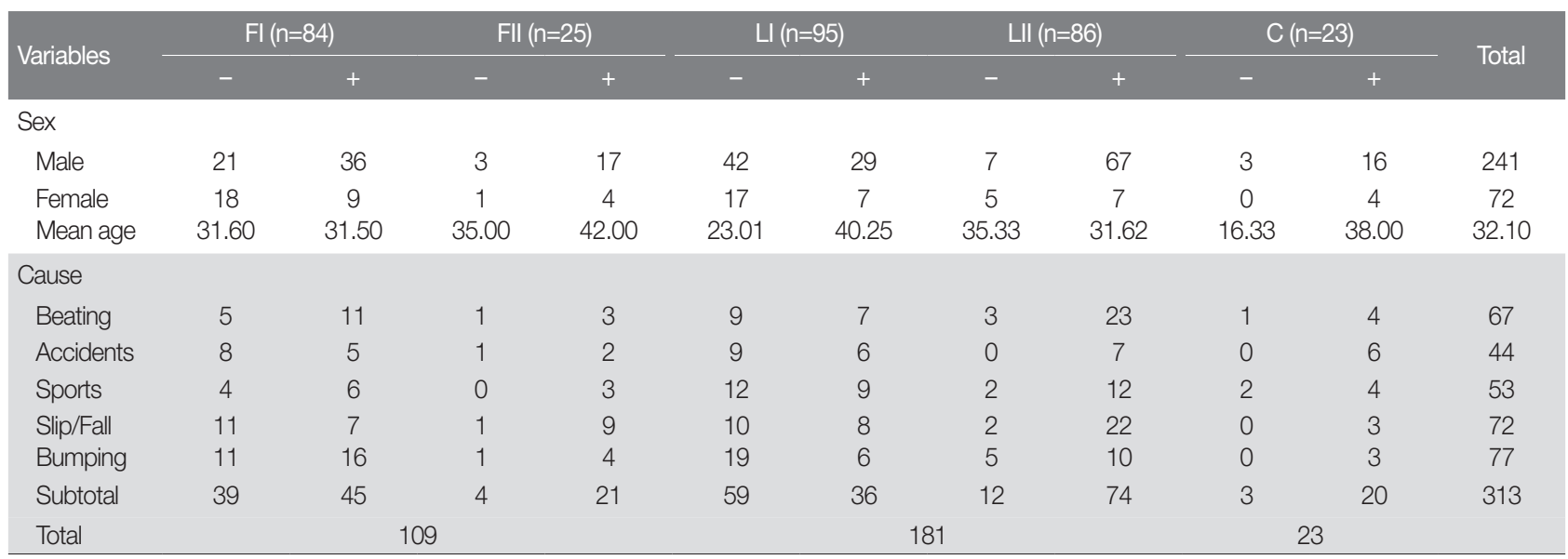

FI, frontal impact group type I; FII, frontal impact group type II; LI, lateral impact group type I; LII, lateral impact group type II; C, comminuted fracture group; -, no presence of septal fracture or deviation; +, presence of septal fracture or deviation.

Table 3. Operation result

\begin{tabular}{|c|c|c|c|c|c|c|c|c|c|c|c|c|c|c|c|c|}
\hline \multirow{2}{*}{$\begin{array}{l}\text { Operation } \\
\text { result }\end{array}$} & \multicolumn{3}{|c|}{$\mathrm{FI}$} & \multicolumn{3}{|c|}{ FII } & \multicolumn{3}{|c|}{$\mathrm{LI}$} & \multicolumn{3}{|c|}{ LII } & \multicolumn{3}{|c|}{ C } & \multirow[b]{2}{*}{ Total } \\
\hline & - & + & $\begin{array}{l}\text { Sub } \\
\text { total }\end{array}$ & - & + & $\begin{array}{l}\text { Sub } \\
\text { total }\end{array}$ & - & + & $\begin{array}{l}\text { Sub } \\
\text { total }\end{array}$ & - & + & $\begin{array}{l}\text { Sub } \\
\text { total }\end{array}$ & - & + & $\begin{array}{l}\text { Sub } \\
\text { total }\end{array}$ & \\
\hline Excellent & $\begin{array}{c}28 \\
(71.79)^{a)}\end{array}$ & $\begin{array}{c}28 \\
(62.22)^{b)}\end{array}$ & $\begin{array}{c}56 \\
\left.(66.67)^{c}\right)\end{array}$ & $\begin{array}{c}2 \\
\left(50.00^{a}\right)\end{array}$ & $\begin{array}{c}11 \\
(52.38)^{b)}\end{array}$ & $\begin{array}{c}13 \\
\left.(52.00)^{c}\right)\end{array}$ & $\begin{array}{c}41 \\
(69.49)^{a)}\end{array}$ & $\begin{array}{c}20 \\
(55.56)^{b)}\end{array}$ & $\begin{array}{c}61 \\
(64.21)^{c)}\end{array}$ & $\begin{array}{c}6 \\
(75.00)^{a}\end{array}$ & $\begin{array}{c}48 \\
(61.54)^{b)}\end{array}$ & $\begin{array}{c}54 \\
(62.79)^{c)}\end{array}$ & $\begin{array}{c}1 \\
(33.33)^{\mathrm{a})}\end{array}$ & $\begin{array}{c}4 \\
\left.(20.0)^{b}\right)\end{array}$ & $\begin{array}{c}5 \\
(21.74)^{c)}\end{array}$ & $\begin{array}{c}189 \\
(60.38)^{d)}\end{array}$ \\
\hline Good & $\begin{array}{c}8 \\
(20.51)\end{array}$ & $\begin{array}{c}12 \\
(26.67)\end{array}$ & $\begin{array}{c}20 \\
(23.81)\end{array}$ & $\begin{array}{c}2 \\
(50.00)\end{array}$ & $\begin{array}{c}6 \\
(28.57)\end{array}$ & $\begin{array}{c}8 \\
(32.00)\end{array}$ & $\begin{array}{c}18 \\
(30.51)\end{array}$ & $\begin{array}{c}14 \\
(38.89)\end{array}$ & $\begin{array}{c}32 \\
(33.68)\end{array}$ & $\begin{array}{c}2 \\
(25.00)\end{array}$ & $\begin{array}{c}26 \\
(33.33)\end{array}$ & $\begin{array}{c}28 \\
(32.59)\end{array}$ & 0 & $\begin{array}{c}11 \\
(55.00)\end{array}$ & $\begin{array}{c}11 \\
(47.83)\end{array}$ & $\begin{array}{c}99 \\
(31.63)\end{array}$ \\
\hline Fair & $\begin{array}{c}2 \\
(5.19)\end{array}$ & $\begin{array}{c}3 \\
(6.67)\end{array}$ & $\begin{array}{c}5 \\
(5.95)\end{array}$ & 0 & $\begin{array}{c}4 \\
(19.05)\end{array}$ & $\begin{array}{c}4 \\
(16.00)\end{array}$ & 0 & $\begin{array}{c}2 \\
(5.56)\end{array}$ & $\begin{array}{c}2 \\
(5.56)\end{array}$ & 0 & $\begin{array}{c}3 \\
(3.85)\end{array}$ & $\begin{array}{c}3 \\
(3.49)\end{array}$ & $\begin{array}{c}1 \\
(33.33)\end{array}$ & $\begin{array}{c}3 \\
(15.00)\end{array}$ & $\begin{array}{c}4 \\
(17.39)\end{array}$ & $\begin{array}{c}18 \\
(5.75)\end{array}$ \\
\hline Poor & $\begin{array}{c}1 \\
(2.56)\end{array}$ & $\begin{array}{c}2 \\
(4.44)\end{array}$ & $\begin{array}{c}3 \\
(3.57)\end{array}$ & 0 & 0 & 0 & 0 & 0 & 0 & 0 & $\begin{array}{c}1 \\
(1.28)\end{array}$ & $\begin{array}{c}1 \\
(1.16)\end{array}$ & $\begin{array}{c}1 \\
(33.33)\end{array}$ & $\begin{array}{c}2 \\
(10.00)\end{array}$ & $\begin{array}{c}3 \\
(13.04)\end{array}$ & $\begin{array}{c}7 \\
(2.24)\end{array}$ \\
\hline Total & 39 & $\begin{array}{c}45 \\
(53.57)^{e)}\end{array}$ & 84 & 4 & $\begin{array}{c}21 \\
(84.00)^{e)}\end{array}$ & 25 & 59 & $\begin{array}{c}36 \\
(37.89)^{e)}\end{array}$ & 95 & 8 & $\begin{array}{c}78 \\
(90.70)^{e)}\end{array}$ & 86 & 3 & $\begin{array}{c}20 \\
(62.79)^{e)}\end{array}$ & 23 & 313 \\
\hline
\end{tabular}

Values are presented as number $(\%)$.

FI, frontal impact group type I; FII, frontal impact group type II; LI, lateral impact group type I; LII, lateral impact group type II; C, comminuted fracture group; -, no presence of septal fracture or deviation; + presence of septal fracture or deviation.

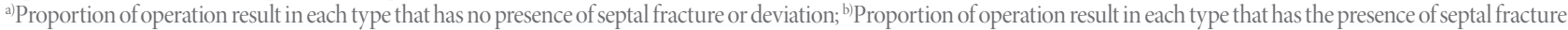
or deviation; ${ }^{\mathrm{c}}$ Proportion of operation result in each type; ${ }^{\mathrm{d}}$ Proportion of operation result in the total group; ${ }^{\mathrm{e}}$ Prevalence of septal fracture in each fracture type. 
Table 4. Proportion of excellent results by fracture type

\begin{tabular}{|c|c|c|c|c|c|c|}
\hline \multirow{2}{*}{ Variables } & \multicolumn{5}{|c|}{ Fracture type } & \multirow{2}{*}{$p$-value } \\
\hline & $F 1^{1)}$ & $\mathrm{FI}^{2)}$ & $\mathrm{LI}^{3)}$ & $\mathrm{LII}^{4)}$ & $C^{5}$ & \\
\hline $\begin{array}{l}\text { Proportion } \\
\text { of excellent } \\
\text { result (\%) }\end{array}$ & 66.67 & 52.00 & 64.21 & 62.67 & 21.74 & $<0.001^{\text {a) }}$ \\
\hline
\end{tabular}

FI, frontal impact group type I; FII, frontal impact group type II; LI, lateral impact group type I; LII, lateral impact group type II; and C, comminuted fracture group. a) Chi-square test; chi-square test with bonferroni correction for multiple comparison result: ${ }^{1,3)},{ }^{3)}>^{2)}>^{5}$.

Table 5. Prevalence of septal fracture by fracture type

\begin{tabular}{|c|c|c|c|c|c|c|}
\hline \multirow{2}{*}{ Variables } & \multicolumn{5}{|c|}{ Fracture type } & \multirow{2}{*}{$p$-value } \\
\hline & $\mathrm{Fl}^{11}$ & $\mathrm{FII}^{2)}$ & $\mathrm{Ll}^{3)}$ & $\left(\mathrm{LII}^{4)}\right.$ & $C^{5}$ & \\
\hline $\begin{array}{l}\text { Prevalence of } \\
\text { septal } \\
\text { fracture (\%) }\end{array}$ & 53.57 & 84.00 & 37.89 & 90.70 & 62.79 & $<0.001^{\text {a) }}$ \\
\hline
\end{tabular}

FI, frontal impact group type I; FII, frontal impact group type II; LI, lateral impact group type I; LII, lateral impact group type II; and C, comminuted fracture group. ${ }^{a}$ Chi-square test; chi-square test with bonferroni correction for multiple comparison result: $\left.\left.\left.{ }^{2},{ }^{4}\right\rangle^{5}\right)^{11}\right\rangle^{22}$.

Table 6. Comparison of proportion of excellent result by septal fracture

\begin{tabular}{lccc} 
& \multicolumn{2}{c}{ Proportion of excellent result (\%) } & \\
\cline { 2 - 3 } Fracture type & - & + & \\
FI & 71.79 & 62.22 & 0.388 \\
FII & 50.00 & 52.38 & 0.843 \\
LI & 69.49 & 55.56 & 0.245 \\
LII & 75.00 & 61.54 & 0.267 \\
C & 33.33 & 20.00 & 0.074 \\
\hline
\end{tabular}

FI, frontal impact group type I; FII, frontal impact group type II; LI, lateral impact group type I; LII, lateral impact group type II; and C, comminuted fracture group.

${ }^{a}$ Chi-square test.
FI, $84.00 \%$ in FII, 37.89\% in LI, 90.70\% in LII, and 62.79\% in C type (Table 3). The $p$-value of the difference between each prevalence of septal fracture by fracture type was $<0.001$, which showed a statistically significant difference. In post-mortem analysis, the prevalence of septal fracture of LII and FII types were higher statistically significantly higher than that of $\mathrm{C}$ type, and that of C type was statistically significantly higher than that of FI type, and that of FI was statistically significantly higher than that of LI type. However, there was no statistically significant difference in the prevalence of septal fracture between the FII and LII type (Table 5)

In each type, the proportion of excellent results, as determined by the presence or absence of preoperative septal fracture, were as follows: in FI type fractures, the proportion of excellent results was $62.22 \%$ and $71.79 \%$ with and without septal fracture, respectively. In FII type, excellent results were obtained in $52.38 \%$ of patients with septal fracture and $50.00 \%$ without septal fracture. In LI type, excellent results were obtained in $55.56 \%$ of patients with septal fracture and in $69.49 \%$ of patients without septal fracture. In LII type, $61.54 \%$ of patients with septal fracture, and $75.00 \%$ without septal fracture showed excellent results. In C type, excellent results were achieved in $20.00 \%$ of patients with septal fracture and $33.33 \%$ without septal fracture (Table 3). Overall the operation in case without septal fracture result was better. However, in each fracture type, there were no statistically significant difference in the proportion of excellent result by septal fracture (Table 6).

Table 7. Complications

\begin{tabular}{|c|c|c|c|c|c|c|c|c|c|c|c|}
\hline \multirow{2}{*}{ Complications } & \multicolumn{2}{|c|}{$\mathrm{FI}$} & \multicolumn{2}{|c|}{ FII } & \multicolumn{2}{|c|}{$\mathrm{LI}$} & \multicolumn{2}{|c|}{ LII } & \multicolumn{2}{|c|}{ C } & \multirow{2}{*}{ Total } \\
\hline & - & + & - & + & - & + & - & + & - & + & \\
\hline Hump nose & 0 & 1 & 0 & 0 & 0 & 0 & 0 & 2 & 0 & 0 & 3 \\
\hline Saddle nose & 1 & 2 & 0 & 0 & 1 & 0 & 0 & 0 & 0 & 0 & 4 \\
\hline Nasal widening & 0 & 1 & 0 & 0 & 0 & 2 & 0 & 0 & 0 & 0 & 3 \\
\hline Deviated nose & 1 & 0 & 0 & 0 & 1 & 0 & 1 & 6 & 0 & 3 & 12 \\
\hline Nasal airway obstruction & 0 & 0 & 0 & 1 & 0 & 0 & 0 & 1 & 0 & 0 & 2 \\
\hline Hyposmia & 0 & 0 & 0 & 0 & 0 & 0 & 0 & 2 & 0 & 0 & 2 \\
\hline Total & 2 & 4 & 0 & 1 & 2 & 2 & 1 & 11 & 0 & 3 & $26(8.31)$ \\
\hline No. (prevalence of complication, \%) & \multicolumn{2}{|c|}{$6(7.14)$} & \multicolumn{2}{|c|}{$1(4.00)$} & \multicolumn{2}{|c|}{$4(4.21)$} & \multicolumn{2}{|c|}{$12(13.95)$} & \multicolumn{2}{|c|}{$3(13.04)$} & - \\
\hline Total & \multicolumn{4}{|c|}{$7(6.42)$} & \multicolumn{4}{|c|}{16 (8.84) } & \multicolumn{2}{|c|}{ - } & - \\
\hline
\end{tabular}

FI, frontal impact group type I; FII, frontal impact group type II; LI, lateral impact group type I; LII, lateral impact group type II; C, comminuted fracture group. - , no presence of septal fracture or deviation; +, presence of septal fracture or deviation. 


\section{Complications}

The various complications observed were hump nose, saddle nose, nasal vault widening, deviated nose, nasal obstruction, and temporary hyposmia.

26 subjects had postoperative complications; nasal deviation was noted in 12 subjects, saddle nose in 4 subjects, nasal widening in 3 subjects, hump nose in 3 subjects, nasal airway obstruction in 2 subjects, and temporary hyposmia in 2 patients (Table 7).

The prevalence of complications according to impact was $6.42 \%$ in the frontal group and $8.84 \%$ in the lateral group. The prevalence of complications according to fracture type was 7.14\% in FI, 4.00\% in FII, 4.21\% in LI, 13.95\% in LII, and 13.04\% in C group.

\section{DISCUSSION}

Postoperative result of nasal bone fracture has been evaluated by complications or patient's satisfaction. However complications and patient's satisfaction are subjective and there is no study about objective outcomes of postoperative result of nasal bone fracture. In this study, we classified postoperative result as 4 grades with immediate postoperative computed tomography, and compared the proportion of excellent results in each fracture type. The proportion of excellent result of FII type (52.00\%) were lower than that of FI, LI and LII types $(62.67 \%-66.67 \%)$ and the proportion of C type (21.74\%) was lower than that of FII type in statistically significant level. This might have been because there was much more displacement and irregularity between fracture segments with the concomitant septal fracture in both FII and C types than in FI and LI types, so the reductions were more complicated. Actually, the prevalence of septal fracture was statistically significantly higher in FII (84.00\%) and C (62.79\%) types than in FI (53.57\%) and LI (37.89\%) types.

Despite a relatively higher prevalence of septal fracture in the LII type (90.70\%), the proportion of excellent results in the LII type was $62.79 \%$, and it was statistically significantly higher than that of FII and C types. After one month, however, the complication rate of LII type (13.95\%) was the highest in all of fracture types.

Moreover, the immediate postoperative result of $\mathrm{C}$ type was not good, and the complication rate (13.04\%) after one month was higher than the rate of FI, FII, and LI type.

As a result, septal fracture occurred more often in FII, LII, and C types than LI and FI types, and there were lower satisfactory operation results in FII and C type and more complications in LII type. In addition to these result, in the proportion of excellent results by septal fracture, all types except FII showed more excellent results in absence of septal fracture without statistically significant. Therefore, septal fracture can be thought to affect post reduction results in nasal bone fractures.

In this study, FII type showed slightly more excellent results in case with septal fracture (52.38\%) than in without septal fracture (50.00\%). This might have been because few cases of FII type without septal fracture were existed. So further study might be needed with large size of cases to compare the FII type with septal fracture from the FII type without septal fracture more exactly.

Meanwhile, in the report of Rhee et al. [9], there are differences between the radiologic findings and the perioperative findings in the degree of septal fracture. In this study, we evaluated the presence of septal fracture by CT scan and perioperative direct examination, and conservative reduction of septal fracture during the nasal reduction was performed. So further evaluation may be needed for evaluating the correlation between the degree of septal fracture and the objective outcomes of the reduction with the data of perioperative findings about the degree of septal fracture.

Postoperative complications of nasal bone fractures-hump nose, saddle nose, hyposmia, and nasal airway obstruction-were observed, and patients were dissatisfied when their noses exhibited deformities that were not noticeable before the injury.

Many studies have reported postoperative complications with nasal bone fractures, and the overall prevalence of complications ranged from $8.4 \%$ to $36.4 \%[1,4,10,11]$. In this study, complications occurred in 26 subjects $(8.61 \%)$, and this result was matched by the objective outcomes as fair in 18 subjects and poor in 7 subjects, whereas one patient showing a good outcome complained about a hump nose.

Lee et al. [4] reported complication rates according to fracture 
type by Stranc classification; in their study, the nasal deformities occurred more in the lateral impact group than in the frontal impact group.

In our study, the prevalence of complication was $8.84 \%$ in the lateral group and $6.42 \%$ in the frontal group. The most frequent complication in the FI group was saddle nose, and, in the LII and C groups, it was a deviated nose. It is thought that the complications correlate to the direction of injury impact.

In conclusion, it seems that surgical results by fracture type were better in FI, LI, and LII types than in FII and C types with statistical significance. The immediate postoperative result of LII was excellent, but, after one month, more complications occurred than in the other types. Additionally, in each fracture type, complications occurred more often in the group with accompanying septal fracture than in the group without it.

\section{REFERENCES}

1. Oh HK, Park YJ, Kim HS, Ryu JY, Kook MS, Park HJ, et al. A recent 5 -year retrospective study on nasal bone fracture.J Korean Assoc Oral Maxillofac Surg 2008;34:230-6.
2. Chung SH, Park J, Choe J, Baek SM. Clinical analysis of satisfaction of nasal bone reduction. J Korean Soc Plast Reconstr Surg 1994;21:98490.

3. Hong SB, Choi BW, Suh IS, Ha JH. Clinical \& radiological evaluation of the nasal bone fractures. J Korean Soc Plast Reconstr Surg 1996;23:1572-82.

4. Lee JH, Park WY, Nam HJ, Kim YH. Complications of the nasal bone fractures according to the stranc classification. J Korean Cleft PalateCraniofac Assoc 2008;9:62-6.

5. Muraoka M, Nakai Y. Twenty years of statistics and observation of facial bone fracture. Acta Otolaryngol Suppl 1998;538:261-5.

6. Han DG, Kim TS. The effect of half day nasal packing in results of closed reduction of nasal bone fracture. Arch Craniofac Surg 2012;13:119-24.

7. Stranc MF, Robertson GA. A classification of injuries of the nasal skeleton. Ann Plast Surg 1979;2:468-74.

8. Lee BM, Han DG. Acute bone remodeling after reduction of nasal bone fracture on computed tomography imaging. Arch Craniofac Surg 2014;15:63-9.

9. Rhee SC, Kim YK, Cha JH, Kang SR, Park HS. Septal fracture in simple nasal bone fracture. Plast Reconstr Surg 2004;113:45-52.

10. Park WY, Kim YH. A clinical study of the nasal bone fracture according to stranc classification. J Korean Soc Plast Reconstr Surg 2008;35:289-94.

11. Lim KR, Kim HI, Ahn SM, Hwang SM, Jung YH, Song JK. Clinical analysis of the nasal bone fracture. J Korean Cleft Palate-Craniofac Assoc 2011;12:81-5. 